\title{
Robust monitoring for high risk underground excavations
}

\author{
M Salcher Pells Sullivan Meynink, Australia
}

\begin{abstract}
This paper discusses methods for monitoring underground excavations in rock, such as tunnels, caverns and underground mine openings. A case study, the excavation of a major railway cavern, is used to present a set of instruments that may be used to obtain valuable data where the failure of a critical instrument has the potential to cause delays to the project. Modern instruments such as shape acceleration arrays, electronic rod extensometers and photogrammetric techniques are compared to conventional devices such as inclinometers, automated total stations and tape extensometers. Some of the practicalities involved in taking readings and installing these systems are highlighted. It will be demonstrated that while the most recent advances in technology may offer convenience when functioning properly, conventional instruments are preferred for a robust monitoring system for high risk underground excavations.
\end{abstract}

\section{Introduction}

Shallow underground excavations, say less than $50 \mathrm{~m}$ deep, in soft sedimentary rocks such as sandstone and shale, can result in surface expressions such as the settlement of roads and tilt of buildings. In urban environments, deformations need to be controlled to ensure that parameters such as surface settlement stay within acceptable limits. As such, it is often considered necessary to monitor the performance of underground excavations and adjacent and overlying infrastructure (e.g. buildings, railway lines, roads) during and after construction.

Major infrastructure projects and mines implement monitoring plans which include pre-defined trigger levels. When these are exceeded, work is required to cease and the situation will need to be re-assessed. As such, it is important that the monitoring system is accurate and reliable.

Designing and installing a reliable monitoring system for a construction or mine site is rarely easy. Water, dust, mud, heat and other work activities provide difficult conditions. It follows that it is easy to install an ineffective monitoring system which has the potential to disrupt works due to erroneous readings. However, the monitoring system should always be the solution that allows work to proceed and must never be the problem that holds up tunnelling. As such, a case can be made for monitoring systems which are simple to install, read and repair.

The example of the excavation of $15 \mathrm{~km}$ of twin railway tunnels and a crossover cavern will be used to illustrate how a robust and simple monitoring system can be established for a high profile underground excavation.

\section{$2 \quad$ Urban tunnelling case study}

The North West Rail Link (NWRL) project in Sydney, constructed by the Thiess John Holland Dragados joint venture, involves, amongst others, the excavation of $15 \mathrm{~km}$ of twin railway tunnels by tunnel boring machine (TBM), five station box cuts and two service shafts. A $160 \mathrm{~m}$ long, $23 \mathrm{~m}$ wide and up to $18 \mathrm{~m}$ high crossover cavern as well as approximately $600 \mathrm{~m}$ of mined tunnels excavated by roadheader are also part of the project. The TBM tunnels are up to $60 \mathrm{~m}$ deep. The cavern crown is approximately $15 \mathrm{~m}$ below a busy intersection and the mined tunnels are about $20 \mathrm{~m}$ underground and underlie existing railway tunnels. The excavations are predominately in sandstone and shale. A description of the geology is presented by Shen et al. (2015). 
The geotechnical monitoring system for the NWRL comprised:

- Approximately 1,000 manually picked up survey points, including prisms, survey pins and marks.

- Photogrammetric railway track monitoring using pixel tracking software.

- Underground automated total station points.

- 16 tape extensometer sections.

- 6 multipoint borehole rod extensometers.

- 32 telltale wire extensometers.

- 25 single point extensometers.

- 31 inclinometers.

- 4 shape acceleration arrays.

- 16 vibrating wire piezometers.

- 24 datalogged open standpipes.

The crossover cavern, being the largest underground excavation in shale in Sydney to date, was considered one of the highest risk aspects of the project. As such, much of the monitoring was focused on the cavern. A plan showing the instruments installed for the crossover cavern, as well as a typical monitoring cross-section is presented in Shen et al. (2015). The monitoring sections had a nominal spacing of $10 \mathrm{~m}$.

Installation of monitoring equipment that could be installed from the surface commenced months before excavation started. The early installation of the system allowed for stable pre-construction baselines to be established. Readings taken during construction could then be reliably compared to these baselines.

Where instruments were installed in boreholes in rock, such as inclinometers, vibrating wire piezometers and extensometers, the boreholes were cored. The core of all holes was geotechnically logged and acoustic televiewer (ATV) surveys were carried out for some holes. This resulted in additional site investigation data and an improved geotechnical model, and also allowed for direct comparison between instrument observations (e.g. displacements observed at a particular depth) and geological conditions (e.g. a shear plane at the point of movement).

The various instruments installed are described below.

\subsection{Survey}

Manually operated total stations were used to monitor:

- Tilt and settlement of buildings.

- Settlement of roads.

- Displacement of piles and shaft walls.

- Convergence of tunnels and the cavern.

Approximately 1,000 prisms, survey pins and survey marks were to be installed for that purpose.

The frequency of reading ranged from daily for surface and underground points close to an advancing face to monthly following the completion of excavation.

The underground survey points in particular were high maintenance as they were frequently disturbed or destroyed by plant or by activities such as shotcreting. Often points were covered by dust. Protecting the points by covering them up during shotcreting was partially successful. Trigger levels were occasionally exceeded due to the instruments having been disturbed. 
Survey accuracy and repeatability for survey by total station was around the $+/-2 \mathrm{~mm}$ mark. Greater accuracy was necessary when the settlements of the road above the cavern approached trigger levels. The designer proposed that digital levelling techniques be adopted to improve accuracy to provide an early indication as to ongoing movement trends.

\section{$2.2 \quad$ Tape extensometer}

The most accurate and most repeatable underground convergence results were obtained by tape extensometer. The tape extensometer sections coincided with optical survey sections and were spaced at $10 \mathrm{~m}$ centres along the cavern. Installation of tape extensometer monitoring points closely followed the advancing face of the initial top heading of the cavern. The intention was that points were to be installed no later than $3.5 \mathrm{~m}$ (less than half a diameter of the first top heading) from the face in order to capture initial deformations. These initial readings could be used for comparison with design assumptions. Later readings could be used to check that the excavation was stable.

Eye bolts were resin grouted in the invert and crown. Every time a tape extensometer cross-section was measured, three independent readings were taken. A thermometer was used to record the air temperature underground to allow the tape extensometer readings to be corrected for temperature effects.

Every odd week or every time the tape was dropped or bent, a correction value was obtained by measuring a stable benchmark offsite, which had been established prior to the first underground use of the tape.

The rigorous enforcement of using temperature and benchmark corrections resulted in a reading repeatability better than $+/-0.5 \mathrm{~mm}$ across readings over 4 months with two different operators. As such, the tape extensometer readings provided the most reliable source of underground convergence data. Tape extensometer readings are compared to total station survey readings in Figure 1. For the purpose of this comparison, the cavern invert is assumed stable.

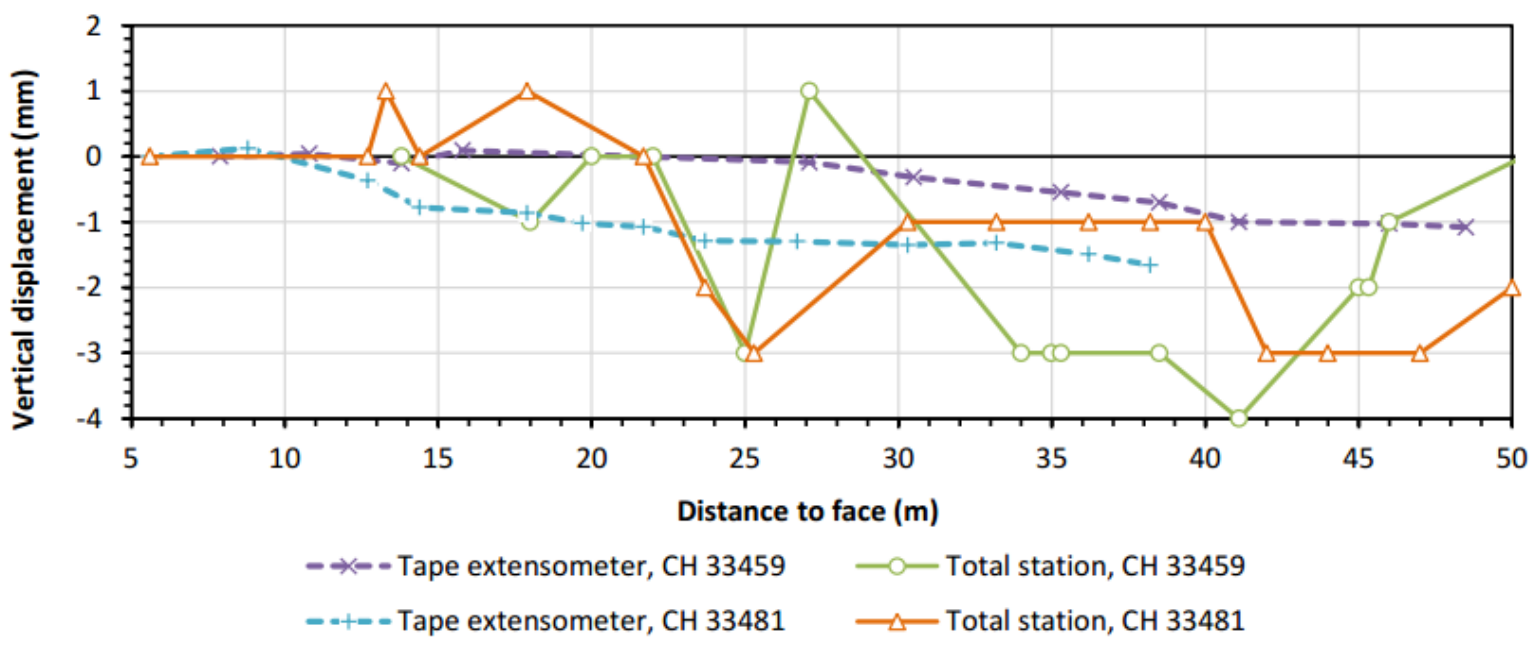

Figure 1 Comparison between tape extensometer and total station survey readings for vertical convergence of the cavern

Reading frequency for the points closest to the cavern face was daily. To ensure that the tape extensometer was available without fail, a backup instrument and two backup steel tapes were kept on site.

The tape extensometer points suffered from similar problems as the underground survey points but to a lesser extent: they were occasionally destroyed or bent by plant or covered in shotcrete. Tape extensometer points in the invert were protected by steel road covers. While this prevented plant from damaging them when tracking over the points, it did not make it any easier to locate them on a surface covered in mud. 


\subsection{Single point extensometers}

A total of 25 single point extensometers were installed along the $15 \mathrm{~km}$ of the tunnel alignment. Areas of deep residual soils and residential areas were targeted. The purpose of these instruments was twofold:

- To provide a stable benchmark for survey readings.

- To allow measurement of shrink-swell movements.

Stable survey benchmarks not affected by shrink-swell soil movement were required to measure surface and building settlement. As such, these instruments were anchored in rock.

The main purpose of the instruments was to help insure the contractor against spurious claims from home owners concerning tunnelling induced damage to their property. The idea was that the contractor would be able to demonstrate that settlements and heave, and as such damage to homes, were not due to tunnelling but rather due to the shrink-swell behaviour of the soil. For that purpose, it was important that the instruments were set back at least $60 \mathrm{~m}$ from the tunnel alignment to avoid impacts due to tunnelling.

The single point extensometers were drilled from the surface using an auger rig. Depending on the depth to rock, the instruments ended up being between 1 and $6 \mathrm{~m}$ long. They comprised top and bottom brass anchors connected by a fibreglass rod encased in a PVC sleeve. The rods were cut to size on site. Just below the top anchor, the PVC sleeve was cut and two tennis balls were inserted. The tennis balls were used to reduce the stiffness of the extensometer. The bottom anchor was set in rock with concrete. Bentonite pellets were then poured down the borehole up to the top anchor. Following this, the top anchor was fixed in the surrounding soil with concrete. This arrangement, shown in Figure 2, allowed the top anchor to move relative to the bottom anchor as the soil settled and heaved.

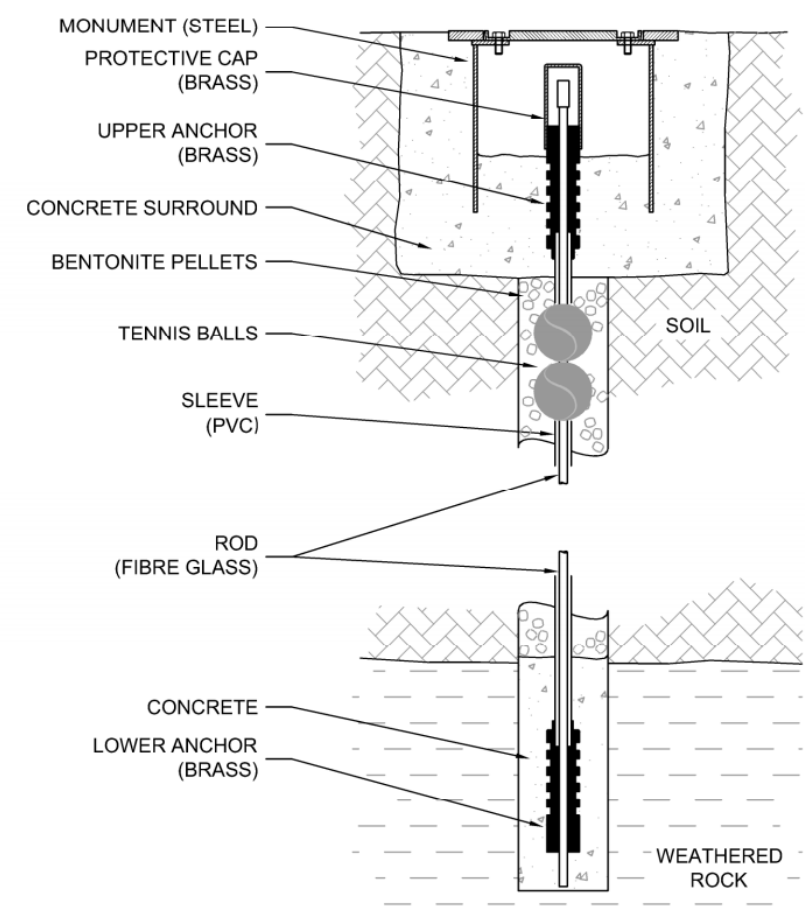

\section{Figure 2 Single point extensometer details}

Salim et al. (2012) have demonstrated the robustness of these instruments. They presented eight years of monitoring data for similar instruments installed for the Epping to Chatswood Rail Link (ECRL).

The extensometers were read manually on a monthly basis using a purpose made adaptor with digital callipers. The adaptor is identical to that presented by Salim et al. (2012). In the thicker, up to $5.5 \mathrm{~m}$ deep clay layers shrink-swell movements exceeding $15 \mathrm{~mm}$ were recorded. Data from the instruments installed 
along the tunnel alignment between the future Showground and Cherrybrook stations are presented in Figure 3. Positive readings show heave, negative readings indicate settlement.

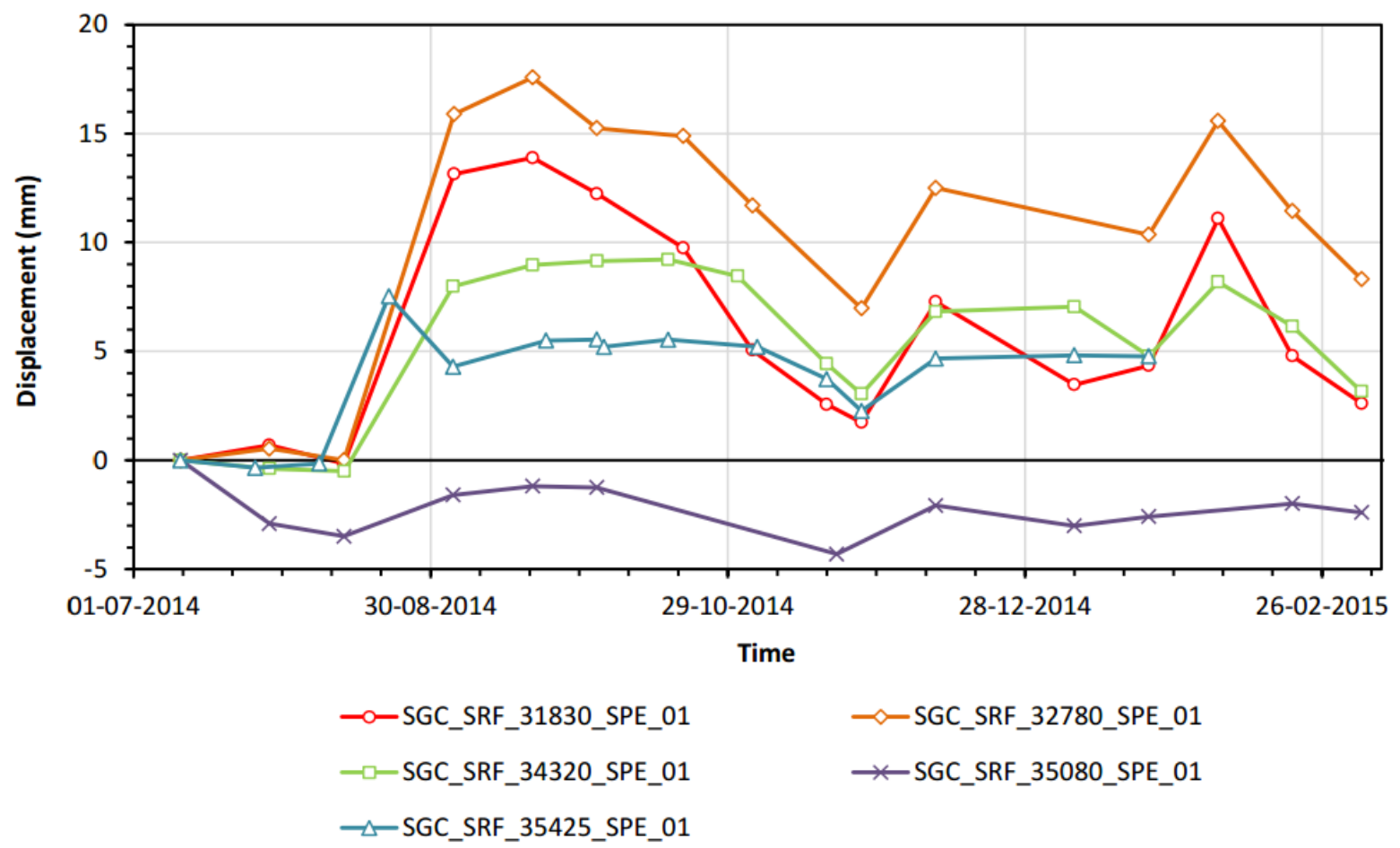

\section{Figure 3 Vertical displacement measured by single point extensometers installed along the tunnel alignment}

\subsection{Wire extensometers}

Wire extensometers were installed in the crown of the first and second top heading of the crossover cavern. These were installed every $10 \mathrm{~m}$ at the same locations as the tape extensometer points.

The wire extensometers were meant to provide a cheap set of monitoring data that could be used to check the readings obtained from other more expensive instruments, such as the grouted rod extensometers.

The instruments consist of two large diameter dial indicators, connected by steel wire to two spring loaded metal anchors. Using extendable rods, the anchors were pushed up $45 \mathrm{~mm}$ diameter holes. The two anchors were placed 3.5 and $7 \mathrm{~m}$ above the crown. The steel wires were then tightened and the dials set to zero.

There is some doubt as to whether the wire extensometers functioned properly. At no time did the instruments show a reading other than zero. Although other instruments (e.g. multipoint rod extensometers and survey points) installed at the same sections suggested crown sag in the order of $5 \mathrm{~mm}$, the wire extensometers showed no displacements. These instruments are commonly used in roadways of underground coal mines, where displacements are much larger. The instruments allow displacements of up to $55 \mathrm{~mm}$ to be captured (i.e. an order of magnitude larger than observed). It may be that the instruments are not able to capture small movements due to multiple millimetres of slack first having to be taken up by a sagging crown. Alternatively, it is possible that the spring loaded anchors slipped in the boreholes drilled in shale. However, this would also be a problem in coal mines.

Monitoring staff used binoculars or got up close in the basket of a drilling jumbo or an elevated work platform in order to read the wire extensometers. 


\subsection{Multipoint rod extensometers}

Six multipoint borehole rod extensometers were installed to monitor crown sag of the initial and second top heading of the cavern. The instruments comprised two stainless steel rods encased in $29 \mathrm{~mm}$ diameter polyethylene tubing terminating in $40 \mathrm{~mm}$ diameter corrugated anchors. The instruments were installed from the surface well before the excavation of the cavern commenced. As far as surface infrastructure allowed, the extensometers were evenly spaced along the length of the cavern, approximately $25 \mathrm{~m}$ apart. Each extensometer was accompanied by a surface settlement point installed as close as possible to the extensometer head to allow for absolute crown sag to be calculated (i.e. as opposed to only measuring relative displacements between the crown and the extensometer head).

The installation involved coring up to $15 \mathrm{~m}$ deep HQ (96 mm diameter) vertical boreholes. The extensometers were suspended in the holes and grout was pumped using tremie techniques. It was necessary to attach steel reinforcement bars to the extensometers to overcome buoyancy during grouting. The two anchors were located $1 \mathrm{~m}$ and $5 \mathrm{~m}$ above the crown of the cavern. The head of the instrument was accessible from the surface but protected in a flush mounted road cover either encased in a concrete road slab or concreted into soil. Where the borehole was partly in soil, the upper $1.5 \mathrm{~m}$ of the borehole was enlarged and a corrugated PVC pipe was concreted in place prior to commencing coring. This detail is shown in Figure 4 for an electronic extensometer. The extensometer head was then grouted inside the PVC casing. The purpose of the corrugated PVC casing was to create a shear connection between the surrounding soil and the extensometer head. This was not deemed necessary where the head was encased in a concrete road slab.



\section{Figure 4 Corrugated PVC pipe installed prior to drilling to create shear connection between soil and extensometer head}

The following grout mix was used (by weight):

- 1 unit of GP cement.

- 2 units of potable water. 
- 0.2 units of bentonite powder.

This produced a consistency similar to that of hard clay. The same mix was used for grouting all instruments, including inclinometers and vibrating wire piezometers.

Five out of the six instruments were read manually. A depth micrometer was used to measure the distance from the reference ring of the extensometer head to the top end of the steel rods connected to the anchors at depth. Reading these instruments accurately required training of technicians. The monitoring team maintained spare depth micrometers and calibrated these on a regular basis.

Using the above approach, accuracy better than +/-0.5 mm was achieved. Readings for the five manually read rod extensometers (MPE 1, 2, 4, 5 \& 6) as well as one electronic extensometer (MPE 3) are presented in Figure 5.

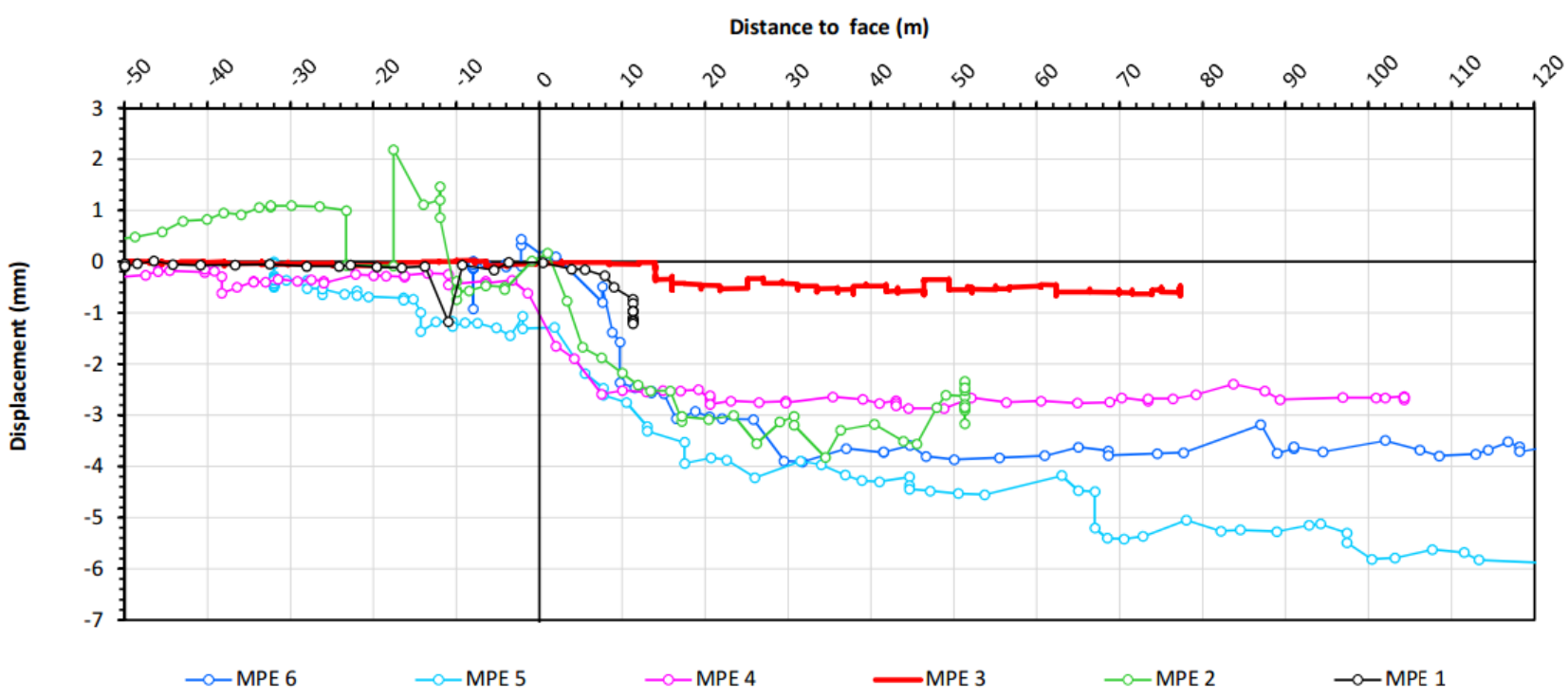

Figure 5 Manually read and electronic rod extensometer readings

The decision to use manually read extensometers over datalogged instruments was made because of the designer's experience with electronic extensometer heads on previous projects. Regardless of whether the instruments are installed in up or downholes, water is a common problem and has the potential to affect the electronics in the head. Checking, maintaining and repairing the head can be difficult if it is encased in grout. Repairs are easier if the head is exposed, but in these cases, the instrument is more likely to become affected by water. While manually read instruments avoid these problems, they require skilled operators. It is important to keep the extensometer head clean. A protective cap may be useful.

One out of the six multipoint rod extensometers could not be read manually due to its location in the centre of the road. A datalogged instrument was installed instead. Since on a previous project the designer experienced problems with exposed electronic extensometer heads, the decision was made here to encase the entire head in grout. Furthermore, drains were installed in the road cover protecting the head, to avoid a build-up of standing water. While the instrument experienced no apparent problems with water ingress during the excavation, its readings were questionable: the instrument showed very little displacements. Readings taken hourly by the electronic extensometer (MPE 3) are shown Figure 5 . These may be compared to the daily manual readings shown in the same figure. Due to the head not being accessible, it was difficult to ascertain whether the readings were representative of ground movement or whether there was a problem with the instrument. Some weeks after completion of the excavation, the instrument failed and stopped reporting data. 


\subsection{Inclinometers}

Of the 31 inclinometers installed for the project, 18 were installed to monitor the crossover cavern. The instruments were installed along the sides of the cavern, spaced at 20 to $25 \mathrm{~m}$ centres. One instrument was placed at the far end of the cavern to monitor the headwall. The inclinometers were installed to a minimum depth of at least $5 \mathrm{~m}$ below the cavern invert, resulting in 35 to $40 \mathrm{~m}$ deep installations. Although intended to be vertical, some of the holes deviated by almost $1.5 \mathrm{~m}$ from the vertical over their $40 \mathrm{~m}$ depth.

Grouting of the inclinometer casing was carried out using tremie techniques. To overcome buoyancy during grouting, a number of methods were tried.

Spring loaded metal inclinometer anchors were tested. These were found to have the potential to open prematurely, hence making it difficult to push the inclinometer casing down the hole and align it with the excavation. In other instances, the borehole walls were too smooth for the anchors to grip, causing the casing to rise during grouting. As such, the anchors were deemed unreliable.

The method that worked best was filling the inclinometer casing with water and lowering drill rods down the casing. Where overhead power lines prevented long drill rods to be utilised, a metal chain was used instead. The combined weight of the water in the casing and the drill rods or the chain was sufficient to overcome buoyancy to prevent the inclinometer casing from rising.

The inclinometers were able to capture shear displacements of about $20 \mathrm{~mm}$ in magnitude at distinct planes before becoming unusable due to the inclinometer probe not being able to pass up and down the casing any longer. An example plot of readings taken in the sidewalls of the cavern is presented in Figure 6. For comparison, readings taken by a shape acceleration array installed on the opposite side of the cavern is also shown.
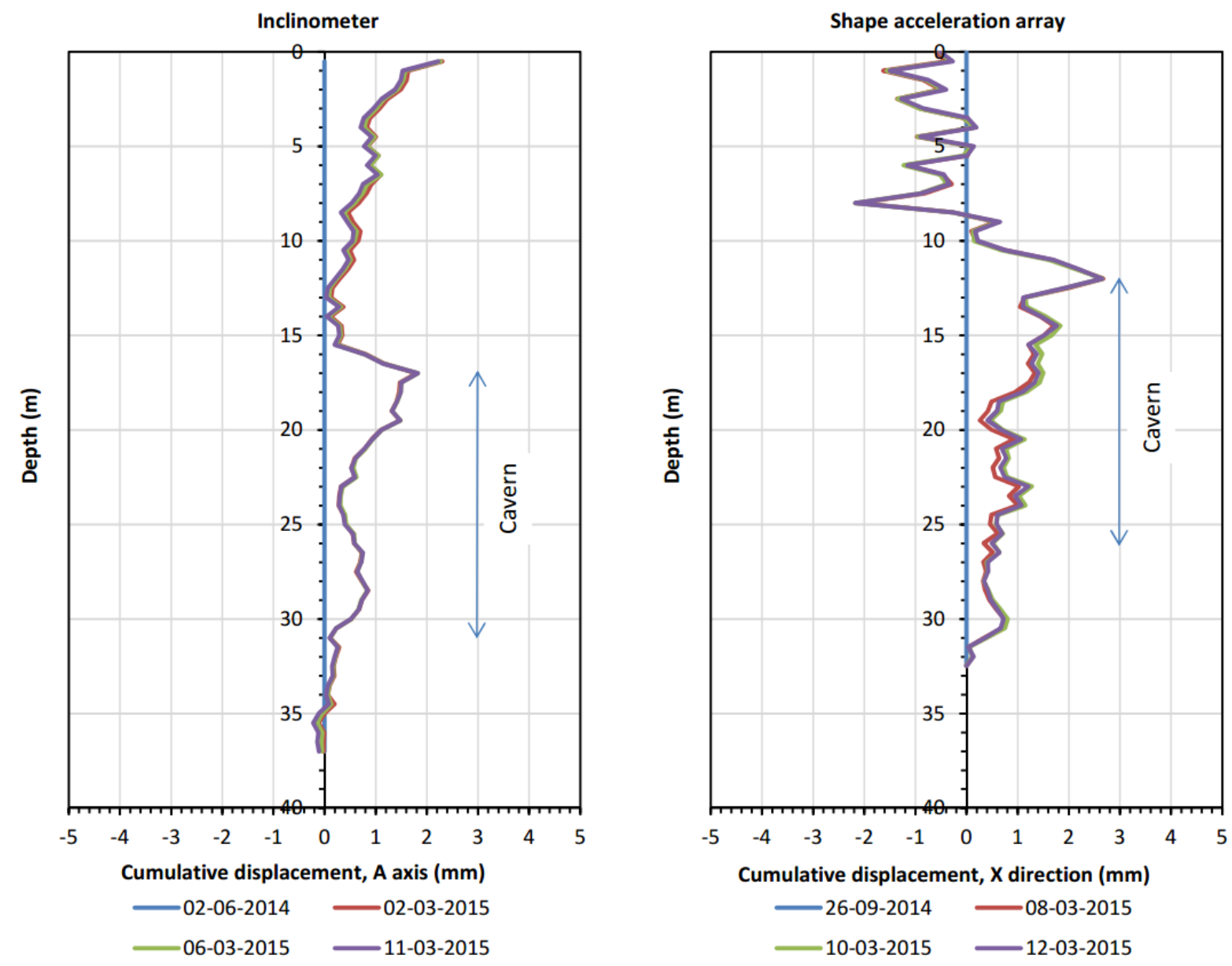


\section{Figure 6 Inclinometer and shape acceleration array readings taken in the cavern sidewall}

After correcting for bias errors, the inclinometers provided readings with errors of about $+/-1 \mathrm{~mm}$. To achieve this accuracy it was necessary to maintain the equipment (i.e. probe and reel) required for reading the instruments. It was important that the probe was not knocked (e.g. by putting it unprotected in the tray of a truck) or otherwise damaged. As with all other essential monitoring gear on the project, a spare probe was maintained. This meant that one probe could be sent to the manufacturer for repairs or re-calibration while the other was still in use.

Nevertheless, the probes were damaged over time and errors became apparent in the readings. While initially it had been possible to interchange probes without a significant effect on readings, less than one year into the project, it was necessary to assign a specific probe to each inclinometer installation to improve repeatability.

During construction, some of the inclinometer installations were damaged. This was mostly due to rock and cable bolting. The bolts were drilled through the inclinometer casing and grout was pumped into the casing. In some instances, it was possible to repair the damage. In other cases, it was deemed cheaper to install a replacement instrument. In the case of repairs, the damage was assessed by video inspection with an endoscope camera. Grout was removed from the casing using high pressure water jets. Following removal of the grout, a cut segment of smaller diameter aluminium inclinometer casing was pushed down the larger diameter acrylonitrile butadiene styrene (ABS) plastic inclinometer casing and placed to cover the damaged section, allowing the probe to pass again.

\subsection{Shape acceleration arrays}

Inclinometers are robust and as such suit high risk excavations because unless they are struck by ground support, there is little that can go wrong once the instrument is installed. No electronics are involved except in the read-out equipment and probe but such damage can be handled by having redundant gear available. However, using inclinometers installed at a busy intersection was not considered viable due to the costs of traffic control required for taking readings. Similar to what was done with the electronic extensometer in the same intersection, a remotely read and datalogged alternative was necessary.

Three shape acceleration arrays were installed to monitor the crossover cavern and a fourth was installed to monitor a section of the Castle Hill station excavation, which was of particular concern to the designer.

A shape acceleration array (SAA) comprises a string of tilt sensors. These are spaced half a metre apart and are protected by stainless steel braid. The sensors are able to measure the shape of the SAA. The readings can be presented in the same way as inclinometer data.

The SAA installations for the crossover cavern were detailed to be redundant: the SAAs were installed inside inclinometer casing. In case the SAA failed, it could be removed and an inclinometer probe could be used to continue monitoring.

The installation commenced by installing inclinometer casing and then taking a baseline with an inclinometer probe. Following this, ABS plastic casing for the SAA was assembled on the surface. Centralisers were screwed onto the outside of the ABS casing in intervals of $0.5 \mathrm{~m}$ (i.e. matching the intervals of the SAA tilt sensors). Two types of centralisers were used: smooth centralisers and 'spider' centralisers with four 'legs'. The smooth centralisers ensured that movement experienced by the outer inclinometer casing was transferred to the inner ABS casing. The 'spider' centralisers were used to align the $A B S$ casing and prevent unwanted rotation (the four 'spider legs' ran inside the four grooves of the inclinometer casing). The SAA was then inserted into the ABS casing and put into compression by screwing a PVC pipe fitting to the top of the ABS casing. By putting the SAA in compression, its joints expand such that they are in contact with the casing, allowing deformations experienced by the casing to be transferred to the SAA. 
The SAAs were connected to dataloggers, some of which required manual data downloads, others transmitted data to an FTP server via the GSM network. The dataloggers were set to take hourly readings.

The SAAs appeared to experience a couple of millimetres of drift prior to the commencement of cavern excavation. Aside from that, the accuracy of the SAAs as installed was comparable to the inclinometers. This is demonstrated in Figure 6, which compares readings from an inclinometer in the cavern sidewall with an SAA installed in the opposite wall.

During the installation, a crucial step is to ensure that the joints of the SAA casing are properly glued and that the glue has set. Since the SAA casing is suspended from the top of the inclinometer casing, it needs to hold the weight of the SAA (tens of kilograms, depending on length). If a casing joint breaks, it will be time consuming to retrieve and repair the casing and complete the installation. In the long term, the glued joints may be an issue of robustness.

Except for the above mentioned issues, no problems were encountered with the instruments once they had been installed successfully. The SAAs appear to be sufficiently waterproof.

\subsection{Groundwater monitoring}

Groundwater levels were monitored using datalogged vibrating wire piezometers (VWPs) and HOBO piezometers. 16 VWPs were installed surrounding shafts and the cavern. 24 HOBO piezometers were used along the tunnel alignment.

The vibrating wire piezometers were generally installed 10 to $30 \mathrm{~m}$ from underground excavations and shafts. Their purpose was to confirm that the drawdown due to excavation was as expected and that groundwater pressures were not higher than assumed for the design of the works. The VWPs were grouted in cored boreholes. The instruments generally worked well and showed reasonable results with the following exceptions:

- Where initially dataloggers had to be installed below the ground surface, water penetrated the canisters protecting the electronics, causing a couple of dataloggers to fail after approximately eight months. This situation was rectified by re-installing the dataloggers above ground surface.

- The thermistor sensors of a couple of VWPs stopped working after approximately 10 months, though the pressure transducers continued to function normally. The instruments were between 15 and $50 \mathrm{~m}$ deep. The manufacturer attributes a series of lightning strikes in the immediate vicinity of the site to have damaged the instruments. However, since the instruments were deep enough such that their temperature had been sufficiently stable over many months, it was reasonable to continue to use the pressure data and assume a constant temperature at depth.

The HOBO piezometers were used to record the water level in open standpipes. HOBO is a brand of piezometer that comes as a single unit which contains the pressure transducer and the datalogger. The unit is suspended in the water from a steel rope. When the instrument is to be read, the unit needs to pulled out of the standpipe and connected to a laptop using a contactless optical adaptor. The HOBO piezometers proved to be robust. No instrument failed.

\section{$2.9 \quad$ Railway track monitoring}

Two tunnels excavated by roadheader in sandstone near the existing Epping train station pass underneath existing railway tracks on the surface and in the tunnels of the Epping to Chatswood Rail Link (ECRL). The vertical distance from the crown of the North West Rail Link (NWRL) tunnels to the existing railway tracks on the surface is about $20 \mathrm{~m}$. The vertical separation between existing and newly excavated tunnels is as little as $6.5 \mathrm{~m}$. Near Epping stations the existing ECRL tunnels and the newly constructed NWRL tunnels are at a similar level separated by a $3 \mathrm{~m}$ wide rock pillar. 
Stringent track displacement limits were required by Sydney Trains. Near the rock pillar between the existing and new tunnels, it was required for horizontal displacements not to exceed $5 \mathrm{~mm}$, necessitating accurate and reliable monitoring.

A photogrammetric system was used to monitor the surface railway tracks. Multiple digital cameras were set up to take photographs of the rails. Pattern recognition and pixel tracking software was used to calculate displacement of tens of points along the rails.

This system did not produce reliable results:

- Frequently monitoring points were missed by the cameras.

- Often the calculated displacements well exceeded trigger levels at one point in time but returned to near zero an hour later.

Since the reliability and accuracy of this system was not satisfactory, it was replaced by manual nightly digital levelling while the photogrammetric system was serviced. The levelling produced sensible results which confirmed that the tracks were not moving.

A different monitoring system was used underground in the existing ECRL tunnels. Automated total stations were installed with survey prisms mounted on the rock pillar between the NWRL and ECRL tunnels and close to the railway sleepers. A plan of prisms installed in the ECRL tunnels is shown in Figure 7. Also shown on this figure are the existing ECRL stub tunnels which connect the NWRL tunnels to the underground Epping station. The automated readings demonstrated a high repeatability and allowed tunnelling to proceed as the pillar became narrower and the tunnel face approached Epping station. The readings were accurate enough for the project team to be confident that pillar movements were well below the $5 \mathrm{~mm}$ red trigger level. Horizontal pillar displacements measured in the ECRL downline tunnel as the NWRL tunnel face approached the train station are presented in Figure 8.

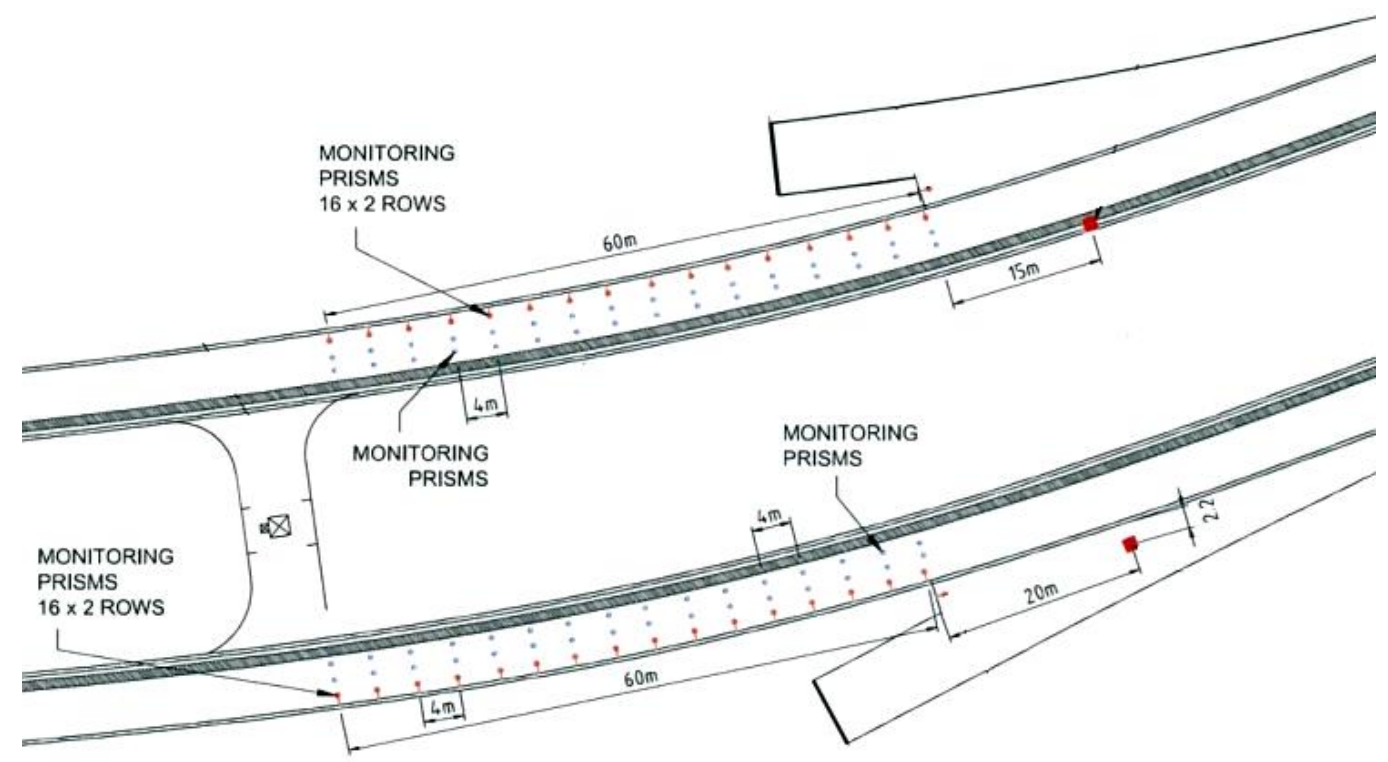

Figure 7 Plan of prisms installed in ECRL tunnels 


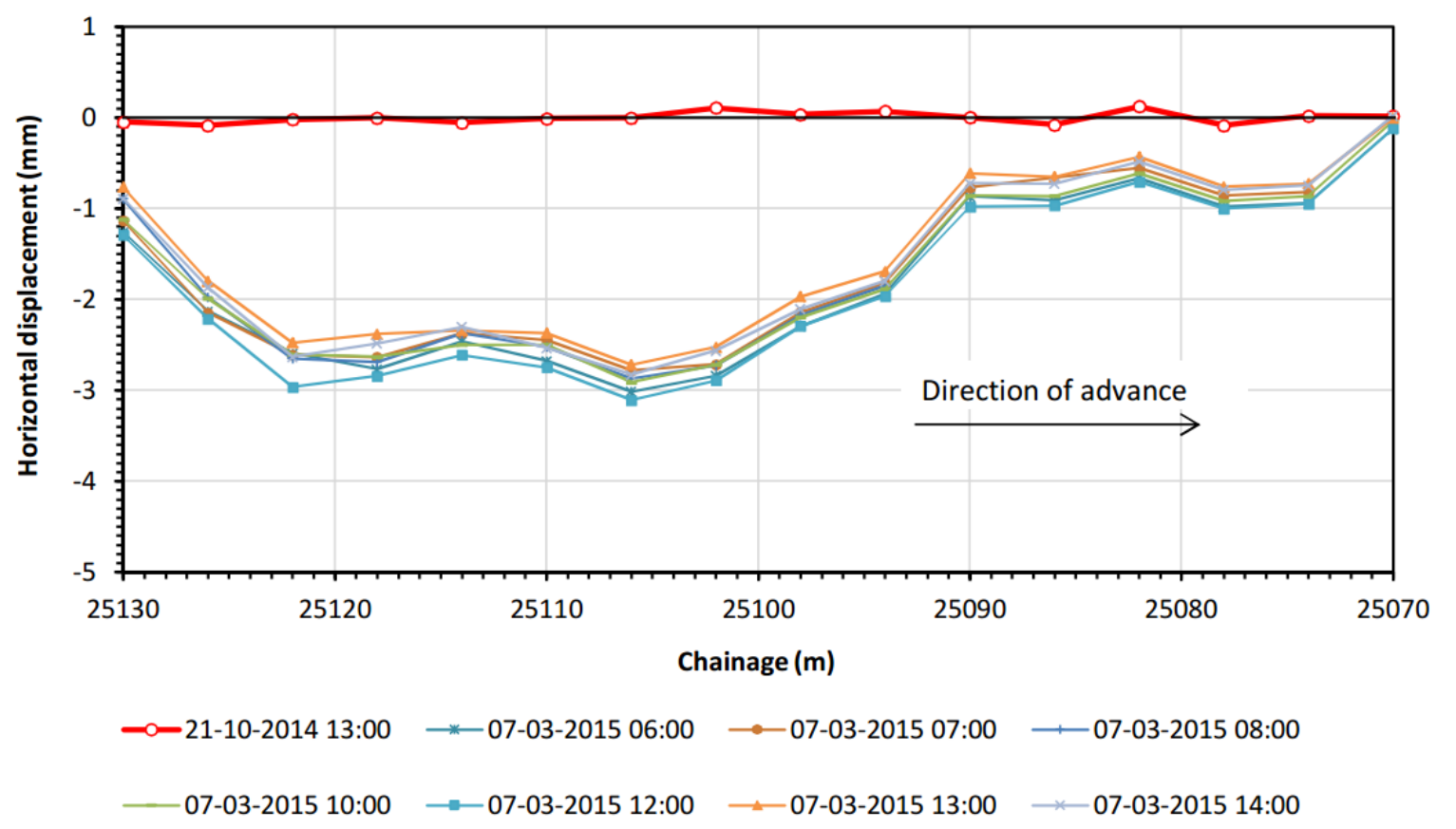

Figure 8 Horizontal displacement of the rock pillar separating the NWRL and ECRL tunnels

\section{Discussion}

It was demonstrated that a reliable and accurate monitoring system for underground excavations can be set up using proven conventional technologies, such as:

- Survey by total station.

- Automated total stations.

- Tape extensometers.

- Manually read borehole rod extensometers.

- Inclinometers.

These conventional technologies are more labour intensive in regards to taking readings when compared to the latest developments in monitoring technology. Furthermore, they require skilled personnel to collect these readings. The resulting data is of a similar level of accuracy as that produced by newly developed modern techniques, which may include:

- Shape acceleration arrays.

- Electronic extensometers.

- Photogrammetric displacement tracking technology.

However, the main difference is that conventional monitoring systems are cheaper, easier and faster to install, less likely to break down and require little maintenance. They are less likely to suffer from installation problems. If they do break down, they are often easier to repair than their state-of-the-art counterparts.

The assumption that the high installation cost of the most modern system is quickly offset by the automated nature of the instruments, requiring near to no labour for monitoring, can be erroneous. The reality is that it often takes significant effort to sort out teething problems. The schematic graph in Figure 9 is based on the author's experience and shows in an exaggerated manner the possible disconnect between 
the planned and actual performance of a state-of-the-art automated monitoring system with the performance of a conventional set-up.

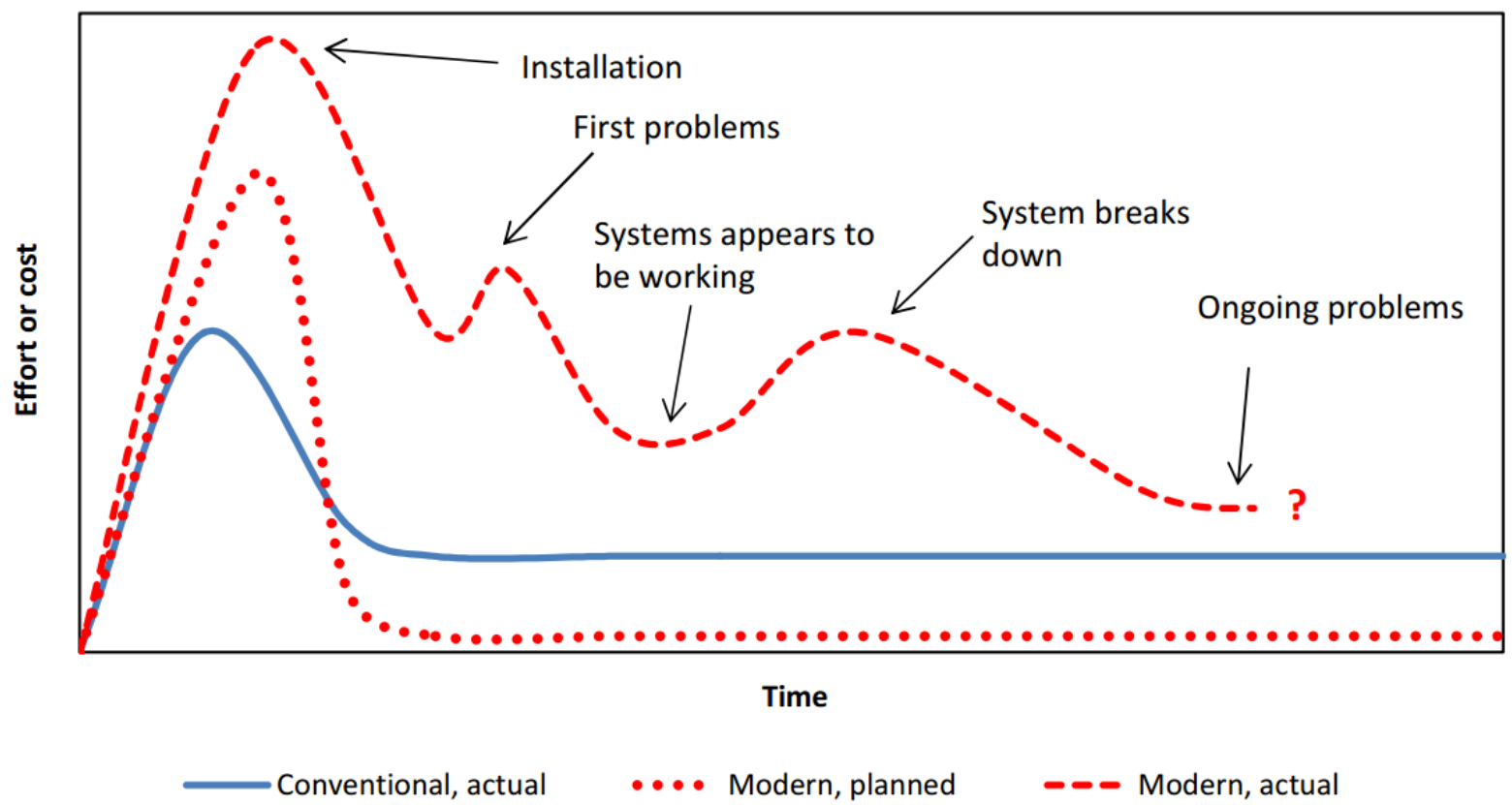

\section{Figure 9 Possible relationship between time and effort of installing and maintaining conventional and modern monitoring systems}

The initial peaks in effort (or cost) represent the amount of work required to install the monitoring system. The conventional system is shown to require less effort for installation. However, as time goes on continuous effort is required to collect monitoring data. Ideally, the modern system, although it requires additional effort for installation, avoids this problem through automation. However, in the author's experience on a number of projects, this is only partly true. The installation may be more complex than envisioned, indicated by the higher than planned peak in effort shown in Figure 9. Furthermore, there may have been problems with the installation which only become apparent at a later stage, requiring additional effort. The system may then perform as expected for some time while it is closely watched, but is likely to break down again, requiring more work for repairs. After some time the major problems may have been resolved but ongoing issues crop up requiring continuous effort to ensure readings are sensible.

The breakdown of a monitoring system is unlikely to occur at a time convenient to the project. The system may well fail when it is needed most. For example, a large rainstorm event which causes an unstable slope to move, may also damage electronically controlled slope monitoring equipment.

If a complex system breaks down, it can take weeks or more until the problems are fixed. In the best case, the data from malfunctioning monitoring systems are ignored. If the system monitors a critical component of the project, such as a railway track, it may be necessary to find an alternative while the instrumentation is repaired. In the worst case, a malfunctioning monitoring system causes delays to the project by providing inaccurate results. At that stage, monitoring has ceased to be the solution that allows the contractor to push on confidently with the excavation. The monitoring system has become the problem that holds up work.

On the other hand, a functioning monitoring system can lead to reduced construction time (e.g. through increased advance lengths or reduction in ground support requirements). On the North West Rail Link (NWRL) project, as the tunnels advanced by roadheader were getting close to the existing underground Epping train station, the project contract had initially required that a 'bolt one - cut one' sequence was adopted (i.e. the advance length was restricted to allow only one ring of rock bolts to be installed). However, automated total stations monitoring pillar and track movements in the existing ECRL tunnels and surveyors manually picking up convergence targets in the newly excavated NWRL tunnels, enabled the 
project team to demonstrate to the infrastructure owner (Sydney Trains) that it would be safe to double the advance length.

\section{Conclusion}

A reliable, robust and accurate underground monitoring system can be established using conventional and proven technology. Such a system allows the contractor to demonstrate to themselves and their client that the design and construction methodology is performing as planned or better. This may allow for productivity increases through reduced construction time or less rigorous ground support requirements.

While the most recent developments in monitoring technology may offer great convenience they are not recommended for monitoring high risk excavations where the failure of an instrument has the potential to hold up construction (e.g. by providing inaccurate results).

Where possible and where doing so is not excessively labour intensive, manually read instruments are preferred over datalogged devices. Dataloggers have the potential to become damaged, especially by water. This often leads to at least a few days of lost data.

Where instruments are manually read, it is important to establish stable benchmarks such that invalid readings due to damaged or worn equipment can be corrected. Tape extensometers and micrometres are examples where this is readily achieved. Sub-millimetre accuracy is possible if the equipment is properly maintained and readings are appropriately corrected.

If for some reason (e.g. excessive traffic control costs) conventional instruments are not a feasible option, it is prudent to have an alternative system in place. Examples are the shape accelerations arrays installed in the intersection above the NWRL crossover cavern, which can be reverted to conventional inclinometers if required.

Finally, for high risk excavations it is sensible set up redundant systems by installing multiple types of instruments which measure the same or a similar property. For example, total station survey and tape extensometers can be used to measure convergence and telltale wire extensometers as well as grouted rod extensometers can be used to capture crown sag.

\section{Acknowledgements}

The author thanks Thiess John Holland Dragados and Transport for NSW for permission to publish this material. The author would also like to thank the engineers, geologists and monitoring technicians involved in the project for their dedication and professionalism, which resulted in a highly successful project.

\section{References}

Salim, A, Clarke, S \& Mostyn, G 2012, 'Eight years of monitoring reactive soils along the Epping to Chatswood Rail Link', in GA Narsilio, A Arulrajah \& J Kodikara (eds), Proceedings of the 11th Australia New Zealand Conference on Geomechanics (ANZ 2012), Australian Geomechanics Society and the New Zealand Geotechnical Society.

Shen, B, Nash, TR, Bertuzzi, R \& Clarke, SJ 2015, 'Use of monitoring data during construction to refine cavern design', in PM Dight (ed.), Proceedings of the Ninth International Symposium on Field Measurements in Geomechanics, Sydney, Australian Centre for Geomechanics, Perth, pp. 397-408. 